\title{
Parenting a child with autism: Considering the stresses, supports and implications for social work practice
}

Mc Cafferty, P., \& McCutcheon, J. (2020). Parenting a child with autism: Considering the stresses, supports and implications for social work practice. Child Care in Practice, 1-17. https://doi.org/10.1080/13575279.2020.1765145

Link to publication record in Ulster University Research Portal

\author{
Published in: \\ Child Care in Practice
}

Publication Status:

Published online: 20/07/2020

DOI:

10.1080/13575279.2020.1765145

\section{Document Version}

Author Accepted version

\section{General rights}

Copyright for the publications made accessible via Ulster University's Research Portal is retained by the author(s) and / or other copyright owners and it is a condition of accessing these publications that users recognise and abide by the legal requirements associated with these rights.

\section{Take down policy}

The Research Portal is Ulster University's institutional repository that provides access to Ulster's research outputs. Every effort has been made to ensure that content in the Research Portal does not infringe any person's rights, or applicable UK laws. If you discover content in the Research Portal that you believe breaches copyright or violates any law, please contact pure-support@ulster.ac.uk. 


\section{Parenting a child with autism: Considering the stresses, supports and implications for social work practice.}

\section{Abstract}

Caring for a child that has Autism Spectrum Disorder (ASD) has implications for parents' social and emotional health and well-being. The following article presents the findings from a review of the literature to help elucidate some of the issues that these parents experience. The article begins by arguing that early intervention is the key to supporting parents that care for children with ASD but that with the current reduction of services to this population of parents, that early intervention is not always possible. The article continues by highlighting some of the emotional and social consequences parents encounter as outlined in the literature. These consequences include heightened levels of stress and anxiety - particularly in mothers - compromised parental mental and emotional health and well-being, depression, isolation, guilt and loneliness. The article offers some recommendations for practice to help mitigate these negative consequences. The article hopes to demonstrate that a systemic, family-centred, trans-disciplinary approach is crucial to alleviating parental stress and that the social work practitioner is ideally positioned to encourage the protective factors which could potentially enhance family resilience. This article will further argue that the impact of caring for a child(ren) with ASD is a family issue, and that specialist training, with regards to children with ASD and the stresses experienced by their parents, should be available to all social work professionals. Finally, in an effort to help policy makers and legislators as well as researchers and practitioners better respond to parental needs, recommendations are made for further research. 


\section{Introduction}

Autism is a lifelong developmental disability. Although certain characteristics may be shared (e.g. difficulties with social interaction, intense and prolonged emotional reactions), as it is identified as a spectrum condition, the diagnosis is often broad since it accepts the uniqueness of each individual. Prevalence studies, regionally, nationally and internationally, give us some insight into the numbers of children that are affected by autism. Regionally, the Department of Health (Northern Ireland) $(\mathrm{DoH}(\mathrm{NI}))(2019)$, place the number of children with ASD at 1 in 34. Nationally, the United Kingdom (UK) wide Millennium Cohort Study, which included data from 18,522 families, suggests that the prevalence of autism is now estimated to be $3.5 \%$ by the time children reach 11 -years of age (Dillenburger et al. 2015). Internationally, World Health Organisation (WHO) (2018) figures suggest that the number of children identified with ASD is 1 in 160. Furthermore, estimates from the Centre of Disease and Control's Autism and Developmental Disabilities Monitoring (ADDM) Network (2014), suggest the number of children identified with ASD to be 1 in 59 . Moreover, recent statistics from Northern Ireland, appear to suggest that autism referrals and diagnoses among children are at an all-time high (DoH, 2019). There are many possible explanations for this apparent increase, including improved awareness, reporting and expansion of diagnostic criteria.

Naturally, this increase has also led to a comparable growth in demand for services for children with autism, mirroring a comparable increase in demand for services from parents that care for children with ASD (WHO, 2018). The request from parents for services possibly reflects the unique difficulties in managing children with ASD. For example, among parents of children with disabilities, those who have children with ASD typically report the highest levels of stress (Neece and Chan, 2017). It is therefore important that we understand the impact on 
parents that care for a child(ren) with ASD, so that we might better appreciate how to respond in a more integrated, targeted, cost effective manner and in a way that best supports parents. In line with recent research which identified the preferred terminology from both families and professionals, we will use the terms 'ASD' and 'autism' when discussing both the impacts and supports (Kenny et al. 2016).

\section{Historical, Legislation and Policy context}

Although the first autism-related report published in Northern Ireland ( $\mathrm{NI})$ by the Task Group on Autism in 2002, legislation was not enacted until 2011, two years after the rest of the UK (Department of Education Northern Ireland (DENI), 2002). Prior to the Autism Act NI (2011), Burrows (2010:3) argues that the context of parenting a child(ren) with ASD in NI was significant as it was "set against a backdrop of a society in transition from decades of political conflict". Furthermore, NI had a "lack of awareness of ASD, lack of investment, legislation and practices to address ASD relative to other countries". Prior to the legislation, $85 \%$ of parents of children with ASD experienced a lack of understanding and support with over $70 \%$ experiencing isolation (Burrows, 2010). Like its counterpart in England, the Autism Act (NI) was based on the principle that individuals with autism were afforded the same entitlements as people with other disabilities. Furthermore, it stipulated that all departments were to work in partnership with people with autism and their families to develop an autism strategy. However, upon the development of the Autism Strategy (2013-2020) and Action Plan (20132016), this partnership ceased.

In 2016, the publication of the Broken Promises Report in NI, identified that the legislation, strategy and action plan had failed to deliver on its promises of help for individuals with autism and their families. The report - which included a survey of over 400 people - highlighted that 
services to support children with autism and their families had become worse rather than better. A recent evaluation of the effectiveness of Early Intervention Support Services in NI found that some of the referrals which involved a child(ren) with ASD, left workers feeling deskilled as they were not trained in the clinical issues surrounding autism (Winter, et al. 2018). Although best practice in assessing, diagnosing and supporting children with ASD should be comprehensive and team-based, it must also be carried out by professionals with specialist skills (NICE, 2012). Over the past five years in NI, diagnoses of ASD among children have increased from 286 to 757 . However, the number of accepted referrals is significantly higher 736 to $1257(\mathrm{DoH}, 2019)$. While there are specialist teams within the five Health and Social Care (HSCT) Trusts in NI, the demand for the service has resulted in lengthy waiting lists and supports. The recent Still Waiting Report (Northern Ireland Children's Commissioner for Children and Young People (NICCY), 2018) highlighted frustrations from children, young people and staff at the difficulties of accessing services. Staff highlighted the issue of reduced funding across the board - both statutory and voluntary - and an over-reliance on family support hubs due to the increased demand. Yet, due to this increased demand for limited services, early intervention is often not happening, and the needs of families are not being met. Recent Australian research found that despite parents acting in a timely manner, the average wait for a diagnosis from the initial appointment was 2 years and 4 months (Gibbs et al. 2019). They suggested that these 'missed opportunities' with regards to ineffective early intervention could be addressed by training professionals about the early indicators. In the Broken Promises Report, one mother stated that "there is no such thing as early intervention in Northern Ireland. How can it be when it takes nearly two years for a diagnosis and there are no resources or services available?" (Autism NI, 2016:17). 
This situation exists despite The Children (Northern Ireland (NI)) Order 1995 (Art.18) applying to all children 'in need', including those with a disability, stipulating that the provision of services to help support parents is a prerequisite for effective parenting. Indeed, under The Carers and Direct Payment Act (NI) 2002, practitioners have a statutory duty to offer a carers assessment and where necessary to provide services to meet those needs. In this, early intervention has been identified throughout policy as being crucial, as the earlier strategies are introduced, "the greater the likelihood that children and their families develop skills to alleviate stress, reduce burden and improve outcomes" (Guastaferro and Lutzker, 2018:8). However, early intervention is being prevented by the creation of policy chimneys that slow down and frustrate the best efforts of HSCTs to fulfil its statutory obligations, leaving children and parents exasperated and stressed. Indeed, by the time services are offered, parental stress and the impact of caring for a child(ren) with ASD can be so significant that it can negate any initial positive effects of interventions (Dempsey, 2009; Osborne et al. 2008). The remainder of this article shall now focus on this, highlighting the particular effects on parents that care for a child(ren) with ASD.

The overall aim of the article therefore is to:

- Critically analyse the current evidence-based research on the impacts on parents who have a child(ren) with autism.

- Provide a critical review of local Northern Ireland (NI), national and international literature, focusing on the impact and stresses of parenting a child with autism.

- Consider the limitations of current evidence-based supports and further address how gaps in services can be met. 
- Identify how social work, alongside other professions, should consider autism as a family issue and recognise the importance of supporting primary caregivers.

- Identify gaps in our knowledge, to provide future researchers "with an opportunity to identify where future studies may be needed" (Hayes and Watson, 2013:630).

Additionally, recent reviews (e.g. Chan et al. 2018) have emphasized the necessity of considering how parenting a child with ASD can potentially impact the family as a whole. Consequently, this review also hopes to expand on this holistic way of thinking by considering the impacts and parental stresses from a social work perspective.

\section{The impact of parenting a child with ASD}

The importance of understanding the impact of parenting a child(ren) with ASD has been highlighted in three recent key reviews published within the last five years. Hayes and Watson (2013) in their meta-analysis of the data returned in 15 studies, compared the impact of parenting stress in children with ASD, Typically Developing (TD) and with other disabilities. This review highlighted that practitioners often have a limited conception of stress and its antecedents, arguing that there is an urgent need to understand this growing phenomenon. Hayes and Watson (2013) argue persuasively that only through understanding stress and its causes can we begin to create more targeted interventions to support the whole family. Yorke et al's (2018:3394) meta-analysis of the data returned in 61 studies found that research in the general population has shown that parenting stress and mental health, although related, are separate concepts, "with each tending to increase the vulnerability to the other". Given this, it is important to understand the individual nuances of the impact of parenting a child with ASD. Also, a recent narrative review of 132 studies identified that the largest concentration of the literature related to parenting a child(ren) with ASD focused on stress (Bonis, 2016). This was 
followed by studies which focused on interventions to manage behaviours. Although these interventions are evidence-based, the review highlighted that parents still continue to report stress. To address why this stress is occurring, this review will highlight the reported maternal and parental stresses and then identify supports beyond behaviour-based interventions which have proven to be effective.

- 'Behavioural issues'

Behaviours which are deemed to be socially inappropriate, challenging and disruptive, are highly prevalent in children with ASD. Research suggests that these behaviours are 3 to 4 times more likely to be present in children with ASD and intellectual disabilities compared to children without (Durand et al. 2018). Indeed, social work researchers have made key contributions to research examining how these behaviours can impact on families. Seltzer et al. (2010) found that due to the 'problem behaviour' linked to children with ASD, parents are likely to report more stress and psychological symptoms such as anxiety and depression. Furthermore, this pattern of stress reaction is comparable to other groups experiencing chronic stress, such as individuals suffering from PTSD. This study highlighted the importance of understanding the potential long-term impact of how these stressors can accumulate over years of caregiving.

\section{- Coping Strategies}

The transactional model of stress and coping highlights how parents perceive the situation and ultimately decide on coping strategies used (Folkman and Lazarus, 1984). Recent research from Australia highlighted how both parents feel "controlled" by ASD, yet mothers reported greater levels of emotion-focused coping such as denial or avoidance (Pepperell et al. 2018:1396). Although a small study of 10 couples, the findings echo earlier qualitative studies which highlight the differing impacts on mothers. However, observations noted 
throughout the interviews and from some of the mothers' comments, indicated that fathers also used emotion-focused coping strategies but where perhaps less willing to share it with strangers. Grey's (2003:634) research, in a sample of 53 parents, highlighted the "differing personal impact" of autism, and how the mothers' presented as "significantly distressed". Interestingly, although the fathers reported more problem-focused coping mechanisms, they highlighted that the most serious impact that their child's autism had on them was indirectly, through the stress experienced by the mothers.

Although this process of stress and coping is unique to each parent, Ang and Loh (2019) suggest that this research has tended to focus on understanding how parents cope with the symptoms and behaviours instead of understanding coping as a moderator of stress in parents. Although previous studies have identified maternal anxiety to have a stronger association with child(ren)'s behaviour problems (Jones et al. 2013), their study of 96 fathers and 106 mothers found that there was not a significant difference in levels of anxiety and depression for both parents. Active avoidance (giving up on oneself, blame, critical, expression of negative feelings) coping emerged as a significant moderator for stress in both mothers and fathers. The researchers identified that due to the method used - self-report questionnaires - that fathers may have adjusted their emotional responses to what they believed to be socially desirable. Furthermore, Ang and Loh (2019) identified that the study was small and not reflective of how parents coping strategies may change over time. They recommended that longitudinal studies are required to address any future transitions.

- Feelings of loss and grief

Research suggests that it is "usual" for the family to grieve the loss of the 'normal' child while coming to terms with it both emotionally and practically (Morgan, 2017:29). For practitioners, there is the importance of recognizing that grief can be "a meaningful reaction to any form of 
significant loss" (Thompson, 2016:36). Furthermore, there is the need to consider the "complex emotions and processes of grief" (Stroebe et al. 2017:468). Indeed, a mother in Grey's (2003:636) study reported that she was in a "state of constant grief". Yet, "the extent and pace" of the grief process is unique to each individual (Morgan, 2017:29). Recent perspectives from Spain highlight that in considering these feelings of grief, mothers experienced more emotional intensity, with the fathers wishing to focus on practical behaviour to help their child (Fernańdez-Alcántara et al. 2016). Further insight from Thailand identified how mothers experienced "intolerable anger, sorrow, distress and uncertainty" (Sukmak and Sangsuk, 2018:747). Although both were small-scale studies, they both identified how mothers can simultaneously experience feeling trapped within their grief yet experiencing constant future worry for their children. Both studies recommended that further quantitative studies be undertaken to evaluate the intensity of the grief symptoms, considering the specific features of ASD.

- Bi-directional nature of attachment

Yirmiya and Shaked, (2005), in their meta-analysis of 17 studies found that the relationship between caregiving quality and attachment is especially relevant to autism, given the parenting difficulties, the increased stress and greater risk of maternal mental health. Recent Australian research by Teague et al. (2018), has explored this further, highlighting the bidirectional nature of attachment. Their study compared 29 parent/child with ASD dyads to 20 children with other developmental disabilities, finding that children with ASD are more likely to experience higher levels of stress, anxiety and attachment insecurity. The study emphasized the role of maternal mental health as predictors of attachment in children, recommending that mothers of children with autism need support in improving their mental health and parenting practice. 
- Future related worries

Levin and Scher's (2016), comparison study found that mothers of children with autism are more likely to report more sleep issues and higher stress than mothers of a typically developing child. Indeed, a United States (US) study of 70 mothers of children with ASD, found that $77 \%$ presented with clinically significant levels of stress (Kiami and Goodgold, 2017). The study also highlighted the need to consider interventions which address the socioemotional impact of parenting a child with ASD, moving away from the focus on behaviours. Research has highlighted how the diagnosis process can be stressful for parents, yet findings from a recent quantitative study highlighted how this long process can actually have a positive impact on maternal stress levels (Reed et al. 2019). In this study of 67 mothers, what was identified to be the most important factor in achieving this positive impact, was the interpersonal skills of the involved professionals. Indeed, taking a strengths-based approach when working with families with autism has been identified to be crucial in promoting positive coping strategies and encouraging resilience (Steiner and Gengoux, 2018).

Chan et al. (2018:28), considered the mediating factors between child ASD symptoms and parental affective symptoms, and how the impacts of this process should be considered within the family. The study highlighted how future-related worry and parenting stress were the strongest mediators between the two. The researchers recognised the study limitations, in that $86.1 \%$ of the 375 participants were mothers, and further addressed the need for a more robust randomised-controlled trial to further evidence whether a family approach is more effective than an individual in promoting the adaptability of families raising children with ASD. Further limitations included the reliance on parents' self-reports, identifying that the results may be subject to common method biases. Yet, the findings highlighted the importance of 
considering a family-focused intervention approach that supports the whole family of a child with ASD.

- Social Isolation

Findings from recent research with 544 caregivers of a child(ren) with ASD, indicated that social isolation can be a major contributor to parental stress (Sim et al. 2018). A major sociological perspective on parenting stress is the stress process model, which helps to explain socially patterned distributions of strains and mental health (Pearlin, 1989). Research identifies mothers of disabled children to be on the edge of society, with many experiencing isolation, loneliness and poor physical and mental health (Shearn and Todd, 2000). Knight (2013) argues that the sociocultural narratives of these mothers, are underpinned by the intersecting identities - the 'self-sacrificing mother', the 'resilient mother' and the 'advocate mother'. Indeed, the combined sociocultural identity of 'mother' and the normative expectation that a disabled child will be supported by the family strongly influences both the role and identity adopted by mothers in this context. This amplifies the marginalization of both mother and child (Zibricky, 2014). A key part of this special mother identity is prioritising the child's needs at all times, however many mothers report to feeling judged by society and family (Cronin, 2018).

- Stigma

Bonis (2016:156) suggests that parental stress "is compounded by the ongoing negative stigma associated with ASD". Recent research from Hong Kong among 424 parents of children with ASD, found that most identified with what Goffman (1963) terms 'courtesy' stigma - due to their association with individuals who are publically stigmatized (Chan and Lam, 2018). A recent US study of 50 mother's highlights this "unique impact" of stigma on families with ASD children compared with other disabilities due to the symptoms not being physical or visible (Chiaraluce, 2018:2899). This study argues that these families are under- 
acknowledged in the discussion of family marginalization. Many of the mothers reported feeling additional pressure from family who simply believed that the child's behaviours required more effective "discipline". Additionally, supporting research has found that older generations may be more likely to blame the parents and "question the credibility" of the autism diagnosis (ladorola et al. 2019:26). Indeed, as reflected in Grey's (2003:637) study, the mother's believed that their husband's, family and people outside the family unit viewed them "as the parent most responsible for their child's behaviour." Practitioners need to be aware of these "blame narratives" and be mindful of how interactions could be perceived as 'power over' instead of 'power with' (Davis and Manago, 2016:80; Dumbrill, 2006). Being mindful of this "relational power" underpins anti-oppressive practice, and skills of empathy are essential to convey an understanding of the lived experiences of the families (Smith, 2008:52).

However, Chiaraluce's (2018:2899) study also highlighted that although the mother's identity may have changed, many experienced the loss of their previous identity in recognition of a new one, empowered by their experience. One mother reported "it's a burden, but it's mine and that makes me feel powerful". Although this study was a small sample which recruited white $(75 \%)$, middle-class (96\%) participants, the focus on how mothers perceived their identity is crucial in understanding the importance of empathic, respectful practice. Further qualitative studies have found that parents of children with autism often report a positive outlook on what is important in life and an increased understanding of themselves (Ooi et al. 2016). Thus, although parents experience high levels of parenting stress, "they simultaneously report having positive experiences with and feelings about their child" (BishopFitzpatrick et al. 2019:76).

- Impact of role specialisation 
The evidence suggests that mothers can often experience greater stress due to differences in role specialization, such as the focus on caregiver demands (Hartley et al. 2014). A recent Italian, cross-sectional study, examined how the subjective and objective burden in families with ASD child compared to families with a child with Down Syndrome and in families of a child with Type 1 diabetes (Picardi et al. 2018). Mothers of children with autism reported greater subjective burden than fathers. In the two other groups, no gender differences were observed in subjective burden, leading the researchers to conclude that mothers may feel overwhelmed when facing the caring demands of supporting children with autism. This was a large sample size - 644 mothers and 536 fathers - and is one of the few papers found which addresses the significance of including the fathers. Indeed, as the authors note, in Italy and across Europe, fathers are involved in the care of their children and should be included in all future research addressing the impact of autism on a family.

A further finding from this study highlighted that the adverse impact on parental work was higher in the ASD group than two others. Indeed, Nomaguchi and Johnson (2016) found that unemployment and inflexible work schedules were related to higher levels of stress - for both mothers and fathers. Morris (2012), in examining the relationship between work and poor mental health between mothers of a child(ren) with autism and mothers of a typicallydeveloping child(ren) found that work can have a positive impact on mental health - especially so for mothers of children with autism as they viewed the workplace as a place of respite.

Longitudinal research has shown support for child emotional and behavioural problems and parent psychological well-being (Bagner et al. 2013). Indeed, a recent 3-year, longitudinal study of 188 families found that child autism symptoms led to an increase in stress in both 
parents; however, the stress was significant for mothers (Rodriguez et al. 2019). Furthermore, this study also highlighted the bi-directional link of this stress - over the 3 years, the four waves of data collection highlighted that this stress was both internalized and externalized by the children (aged 5-12). This particular study is robust in that it separately assessed both mother and father reported measures of child functioning and stress in a longitudinal design. Furthermore, the findings support those of previous studies, emphasizing the potential impact of parenting stress on the whole family (e.g. Zaidman-Zait et al. 2014). However, the study sample was largely White European with middle socioeconomic status and only recruited families with two co-residing parents, thus limiting the generalizability of findings.

These types of social patterns and stresses are best explored through population-based studies which use a representative sample of a large-scale population to increase the generalizability of the findings. Tosika et al. (2011:97) was the first study to separately examine the association of ASD and Intellectual Disability with child behavioural/emotional problems, and maternal mental health, using the population-representative sample of 18,415 children of the 1999 and 2004 Office of National Statistics (ONS) surveys from the UK. Through face-to-face interviews, the study showed the presence of ASD to have "a significant independent association" with maternal emotional disorder. This study further strengthened the internal validity of the findings as it considered the moderating effects of the family's socioeconomic position. In families of high adversity, the presence of low maternal mental health was likely to increase the behaviours of the child. This study is important as it clearly highlights that mothers of a child with autism are more likely to experience higher levels of stress than any other group. Although a study with strong citation indices, it highlights that population-based surveys often only ask one primary caregiver, in this case $94.3 \%$ mothers, emphasizing the gap in the literature in trying to understand the impact on fathers and thus on 
the whole family. Considering how these stresses can impact upon the family is essential the next section will examine how appropriate supports could provide an alleviation of this stress, and potentially build family stress resilience.

\section{Supports to help manage the impact and stresses of caring for a child with ASD}

Research generally concurs with the correlation between the severity of ASD behaviours and the resulting increase in parenting stress (Rodriguez et al. 2019). Applied Behavioural Analysis (ABA), which focuses on observing and measuring the behaviours to be changed, was identified in the 1960's to be a successful intervention when used with child(ren) with ASD, whose behaviours were deemed unmanageable. Wolf et al. (1964) seminal study resulted in the first successful intervention with a child with ASD that was reported in the scientific literature, paving the way for the evidence-based intervention of Applied Behavioural Analysis. Their study focused on a 3-year old boy who was referred to a hospital for people experiencing mental ill-health under the common but inaccurate diagnosis of the time childhood schizophrenia. Through teaching the parents the skills of ABA, this study became the first successful intervention which was reported in the scientific literature. Although, many new contemporary techniques and assessment strategies have been developed which identify the social ecology of autism, ABA remains the most dominant, evidence-based intervention (Guastaferro and Lutzker, 2018).

Yet, recent comparative research has identified how the delivery of ABA interventions can vary between different countries. Liao et al. (2018) examined the perspectives of parents and agencies (who delivered the ABA intervention) in the UK and China. Their results emphasized that in China, there was a parent-focused approach to the intervention, whereas in the UK, professionals tended to work on a one to one basis with the child(ren). While the authors 
acknowledge that there can be no one size fits all approach, their research identified that in China, working closely with the parents led to the belief that having well-trained parents could result in them adjusting the ABA-based intervention "closely to their daily lives" (Liao et al. 2018:22).

Although $A B A$ is a proven evidence-based intervention, widely available in North America, families in Northern Ireland have campaigned for it with no results (Dillenburger et al. 2014). In Northern Ireland, the 'eclectic' approach is favoured, i.e. a combination of different treatments and therapies, which includes diagnosis and support from a number of health-care professionals. Gillen and Keenan (2017) argue that there is no evidence-base for this approach. Furthermore, they suggest that due to the limited knowledge of policy-makers regarding $A B A$ supports, children and families are being denied access to evidence-based supports. Yet, the increasing economic and social cost to families and society "can only be mitigated by effective interventions and supports" (Keenan and Dillenburger, 2018:1). In contrast, Kiami and Goodgold (2017:7) argue that this approach in training parents to manage the child's behaviour "is narrow in scope and fails to address the socio-emotional impact of parenting a child with ASD". Indeed, this focus on behavioural management strategies, arguably fails to address "the types of psychological distress" most often reported by parents (Feinberg et al. 2014). As most of the supports are child-focused, although parenting stress is a "clear target" for interventions, it is rarely addressed (Neece and Chan, 2017:112). Indeed, Factor et al. (2019) would further suggest that how the intervention actually impacts the parent(s) has received even less research attention.

\section{Recommendations for practice.}


Catalano et al. (2018), in their systematic review of 23 studies, identified 3 themes as central to improving the mental health of parents. Using these themes, we address supports identified by the literature as having effective results.

\section{- Access to social support with similar parents}

Catalano et al. (2018) review highlighted that one of the most effective supports was through parenting social support groups. Support groups have been identified as crucial in providing a refuge from the "otherness" which families experience, providing parents with a safe place "to reframe their ideas of ASD, family and identity" (Chiaraluce, 2018:2900). Further longitudinal research with 110 parents over a seven-year period emphasized the importance of strengthening the support networks of parents (Benson, 2016). This research further highlighted that social networks can have a positive effect on parenting efficacy - empowering parents to believe that they themselves have the resources to best support their children. Yet, Picardi et al. (2018) suggest that practitioners need to look for more creative methods to increase social support, beyond support groups. They highlight the importance of interpersonal relationships and recommend that interventions should aim to improve social interactions within the natural social network.

This access to social support is reflected as being especially challenging for underrepresented groups in the research. A recent study from the United States focused on the perspectives of 58 parents from three different cultural groups - black, Latino and Korean (Stahmer et al. 2019). The study also included the perspectives of 55 autism service providers. The families reported that challenges such as language barriers were enhanced by the feeling that they were being judged by practitioners for being a 'failed parent'. The practitioners highlighted that they perceived the family challenges as a lack of engagement. 
Although seeking the views of both families and professionals allowed for a "balanced understanding of the process", the findings revealed that parents especially, wished to have a relationship and trust-based partnership with the service providers (Taylor et al. 2015:69).

\section{- Professional training in skills development}

Findings from a recent narrative review (Bonis, 2016), found that programs dedicated to managing stress which focused on acceptance and commitment had positive results changes in parenting approaches to managing the child's care resulted in minimizing stress. Mothers are better able to set limits while fathers satisfaction with parenting is enhanced (Falk et al. 2014). Strengthening problem-solving skills, have also been identified as an effective support to manage maternal mental health. However, Feinberg et al. (2014: 42), US study, assessed the effectiveness of this support among 110 mothers and concluded that while it was deemed effective at the three-month follow-up, further longitudinal study was required.

In their meta-analysis of 11 studies, Tarver et al. (2019) reviewed the effectiveness of Behavioural Parent Intervention. This review highlighted the difficulties of post-intervention data as only three included a six-month follow up. Yet, it further emphasized that "parents may struggle to know how best to respond to their child and report permissive management strategies" (Tarver et al. 2019:2). This highlights the importance of educating parents, while ensuring that practitioners have the knowledge and skills required to provide this information. Additionally, a recommendation from this paper is that staff are trained in $A B A$ and that this type of intervention is used alongside more traditional methods of intervention in NI.

\section{- Gaining knowledge regarding ASD}


Evidence shows the importance of collaboration - working with a provider "who is willing and able to share appropriate evidence-based information are more satisfied with the health care experience and experience less stress" (Rivard et al. 2015; Bonis, 2016:155). Strategies are needed to teach parents to effectively cope with the stress as well as the daily challenges of managing the family as well as managing the behaviours (Sikora et al. 2013). Health care providers frequently attribute the child's behaviour to poor parenting and disregard parents' concerns (Nealy et al. 2012), yet provider knowledge is critically important in determining a diagnosis as early as possible. Indeed, a common barrier is created by health-care providers' inadequate knowledge of ASD and misconceptions (WHO, 2014). Yet, Neely-Barnes et al. (2011) argues that social workers should have this knowledge and should be taking a systemic approach to encourage all family members, including extended family, to make use of educational resources about autism.

\section{Implications and Recommendations for Practice and research.}

All professionals who work alongside families need to be alert to the possible presence of clinically significant symptoms of stress in parents. Considering the increasing rise of children diagnosed with ASD and the rising number of parents experiencing stress, there is an alarming number of parents who can benefit from, and clearly need, support. Early intervention is a globally recognized framework, and due to the intense nature of the frequent direct work with families, social work practitioners are ideally placed to identify the potential stresses and respond quickly and effectively. Yet, having knowledge of the stresses involved and the available evidence-based supports is essential for practitioners to complete a holistic assessment and to further identify appropriate supports, not just for the child(ren) with ASD, but for the supporting family. The social work profession centres around holistic practice, yet how can this be effective if practitioners have not received training in ASD and how this can 
potentially impact the family? This review recommends that training in ASD, the associated stresses and available interventions should be available to all social work practitioners. To support this training, we recommend that there should be a considerable investment of funds from authorities.

Additionally, in recognizing the crucial need to alleviate parental stress and the potential mental health costs as a result, further research is required in this critical area of practice to further understand interventions that work (Da Paz and Wallander, 2017). By extension, Factor et al. (2019) recognise that there is a gap in the research considering the impact interventions have on parents and support the idea of more research to inform policy and practice.

Furthermore, the literature has identified trends through comparing mothers who have children with autism. Hayes and Watson (2013) suggest that comparative researchers need to move beyond questioning are families who have a child with autism more stressed than those who do not, towards a more in-depth understanding of why these families may be experiencing severe stress, and most importantly, what can be done to provide support and encourage family resilience. Having a child with ASD can "significantly and durably" affect the family system - thus, considering the family unit as a whole "seems critical in ASD-specific research" (Factor et al. 2019:434). Arguably, in support of this, the trends in autism research need to be addressed from a "social work lens", moving away from the individual focus of impact to consider a life course perspective with a systemic focus on the family (BishopFitzpatrick et al. 2019:81). Ultimately, as social work research is concerned with the process of "making a difference to people's lives", practitioners are in an ideal position to identify issues and strive to promote change throughout all areas of practice (Dillenburger, 2004:105). 
Finally, in most of the studies reviewed, the parent who reported their own stresses was also the one who reported on the child's emotional and behavioural issues. As these were most often the mothers, there is the danger that these reports may not accurately represent fathers' experiences of their child's behaviours (Jones et al. 2013). Although most of the research concentrates on the mothers' perspective, social work is based on recognizing the diversity of each family and considering all perspectives. Therefore, research must give a more balanced holistic view and consider the perspectives of the family system. Additionally, most of the recruited samples to ASD research, were white, middle-class, with access to resources. To achieve cultural validity, further research is required among under-represented families of a lower socio-economic status.

Conclusion.

This article has attempted to add to the literature on the impact on parents caring for a child with ASD. This review of the social and emotional impact on parents caring for children with ASD is timely given the increase in the number of children being diagnosed with ASD and the crucial role parents play in their care. The review has highlighted that despite policy and legislation being in place to support parents, its effect tends to lag behind meeting the immediate needs of parents. This hinders the effective delivery of the early intervention of services that can have an ameliorating effect on the stress associated with caring for a child that has ASD. The review has highlighted some of the impacts on parental emotional health and well-being as well as the social implications that parents face as a result of caring for a child with ASD. Recommendations are made for practice as well as for future research. 


\section{References}

Ang, K. Q. P., and Loh, P. R. (2019). Mental health and coping in parents of children with autism spectrum disorder (ASD) in Singapore: An examination of gender role in caring. Journal of autism and developmental disorders, 49(5), 2129-2145.

Autism NI (2016). Broken Promises Report. Belfast: Autism NI. Accessed on 18/05/2019 at: file:///C:/Users/AppData/Local/Packages/Microsoft.MicrosoftEdge 8wekyb3d8bbwe/TempStat e/Downloads/Autism\%20N1\%20Broken\%20Promises\%20Report\%20(1).pdf.

Bagner, D. M. (2013). Father's role in parent training for children with developmental delay. Journal of Family Psychology, vol.27(4), pp.650-669.

Benson, P. R. (2016). The longitudinal effects of network characteristics on the mental health of mothers of children with ASD: The mediating role of parent cognitions. Journal of Autism and Developmental Disorders, vol.46(5), pp.1699-1715.

Bishop-Fitzpatrick, L., Dababnah, S., Baker-Ericzén, M. J., Smith, M. J., and Magaña, S. M. (2019). Autism spectrum disorder and the science of social work: A grand challenge for social work research. Social Work in Mental Health, vol.17(1), pp. 73-92.

Bonis, S. (2016). Stress and parents of children with autism: A review of literature. Issues in Mental Health Nursing, vol.37(3), pp.153-163.

Burrows, R. (2010). Is anyone listening? Belfast: Autism NI. Accessed on 18/05/2019 at: http://www.autismni.org/is-anyone-listening.html

Catalano, D., Holloway, L., and Mpofu, E. (2018). Mental health interventions for parent carers of children with autistic spectrum disorder: Practice guidelines from a Critical Interpretive Synthesis (CIS) systematic review. International Journal of Environmental Research and Public Health, vol.15(2), 341.

Chan, K. K. S., and Lam, C. B. (2018). Self-stigma among parents of children with autism spectrum disorder. Research in Autism Spectrum Disorders, vol. 48, pp. 44-52. 
Chan, K. K. S., Lam, C. B., Law, N. C. W., and Cheung, R. Y. M. (2018). From child autistic symptoms to parental affective symptoms: A family process model. Research in Developmental Disabilities, vol.75, pp.22-31.

Chiaraluce, C. A. (2018). Narratives on the autism journey: "Doing family" and redefining the caregiver self. Journal of Family Issues, vol.39(10), 2883-2905.

Cronin, M. (2018). 'Special Mothers' in Ireland: Gender, Identity and The Social Construction of Caring for a Relative With an Intellectual Disability. International Journal of Care and Caring, vol. 2(4), 575-580.

Da Paz, N. S., and Wallander, J. L. (2017). Interventions that target improvements in mental health for parents of children with autism spectrum disorders: A narrative review. Clinical Psychology Review, vol.51, pp. 1-14.

Davis, J. L., and Manago, B. (2016). Motherhood and associative moral stigma: The moral double bind. Stigma and Health, vol.1(2), 72.

Dempsey, I., Keen, D., Pennell, D., O'Reilly, J., and Neilands, J. (2009). Parent stress, parenting competence and family-centered support to young children with an intellectual or developmental disability. Research in Developmental Disabilities, vol. 30(3), pp. 558-566.

Department of Health (2019). Quarterly autism stats for NI (January - March 2019). Accessed on 18/05/2019 at: https://www.health-ni.gov.uk/publications/quarterly-autism-statistics-nijanuary-march-2019.

Dillenburger K., Jordan J.-A., McKerr L. and Keenan M. (2015). The Millennium child with autism: Early childhood trajectories for health, education and economic wellbeing. Developmental Neuro Rehabilitation, vol.18, pp. 37-46.

Dillenburger, K. (2004) 'Evidence-based practice in Northern Ireland', in Thyer, B.A. and Mansoon, A.F.K. (2004), International Perspectives on Evidence-based Practice in Social Work, Birmingham: Venture Press, pp.97-112.

Dumbrill, G. C. (2006). Parental experience of child protection intervention: A qualitative study. Child Abuse and Neglect, vol. 30(1), pp. 27-37.

Durand, V., Clarke, S. and Strauss, J. (2018) "Positive family intervention; Using optimism to overcome obstacles to successful parenting", in Guasaferro, K. and Lutzker, J. (2018). A guide to programs for parenting children with autism spectrum disorder, intellectual disabilities or developmental disabilities; Evidence-based guidance for professionals. London: Jessica Kingsley Publishers, pp. 53-84.

Factor, R. S., Ollendick, T. H., Cooper, L. D., Dunsmore, J. C., Rea, H. M., and Scarpa, A. (2019). All in the Family: A Systematic Review of the Effect of Caregiver-Administered Autism Spectrum Disorder Interventions on Family Functioning and Relationships. Clinical Child and Family Psychology Review, vol. 22(4), 433-457. 
Falk, N., Norris, K., and Quinn, M. (2014). The factors predicting stress, anxiety and depression in parents of children with autism. Journal of Autism and Developmental Disorders, vol. 44, pp. $3185-3203$.

Feinberg, E., Augustyn, M., Fitzgerald, E., Sandler, J., Suarez, Z. F. C., Chen, N., and Silverstein, M. (2014). Improving maternal mental health after a child's diagnosis of autism spectrum disorder: results from a randomized clinical trial. JAMA Pediatrics, vol.168(1), pp. 40-46.

Fernańdez-Alcántara, M., García-Caro, M. P., Pérez-Marfil, M. N., Hueso-Montoro, C., Laynez-Rubio, C., and Cruz-Quintana, F. (2016). Feelings of loss and grief in parents of children diagnosed with autism spectrum disorder (ASD). Research in Developmental Disabilities, vol. 55, pp. 312-321.

Folkman, S., and Lazarus, S.R. (1984). Stress, appraisal, and coping. New York: Springer.

Gibbs, V., Aldridge, F., Sburlati, E., Chandler, F., Smith, K., and Cheng, L. (2019). Missed opportunities: An investigation of pathways to autism diagnosis in Australia. Research in Autism Spectrum Disorders, vol.57, pp. 55-62.

Gillen, E. and Keenan, M. (2017). When policy decisions for autism treatment in Europe are hijacked by a category mistake. Psychology, vol. 56, pp. 72-78. 60.

Goffman, E. (1963). Stigma: Notes on the management of spoiled identity, New Jersey: Prentice-Hall Inc.

Gray, D. E. (2003). Gender and coping: The parents of children with high functioning autism. Social Science and Medicine, vol. 56(3), pp. 631-642.

Gray, D. E. (2018). Doing research in the real world (4th edn.), London: Sage.

Guasaferro, K. and Lutzker, J. (2018). A Guide to programs for parenting children with Autism Spectrum Disorder, intellectual disabilities or developmental disabilities; Evidence-based guidance for professionals. London: Jessica Kingsley Publishers.

Hayes, S. A., and Watson, S. L. (2013). The impact of parenting stress: A meta-analysis of studies comparing the experience of parenting stress in parents of children with and without autism spectrum disorder. Journal of Autism and Developmental Disorders, vol. 43(3), pp. 629-642.

ladarola, S., Pérez-Ramos, J., Smith, T., and Dozier, A. (2019). Understanding stress in parents of children with autism spectrum disorder: $A$ focus on under-represented families. International Journal of Developmental Disabilities, vol. 65(1), pp. 20-30. 
Johnson, N. L., and Simpson, P. M. (2013). Lack of father involvement in research on children with autism spectrum disorder: maternal parenting stress and family functioning. Issues in Mental Health Nursing, vol. 34(4), pp. 220-228.

Jones, L., Totsika, V., Hastings, R. P., and Petalas, M. A. (2013). Gender differences when parenting children with autism spectrum disorders: A multilevel modeling approach. Journal of Autism and Developmental Disorders, vol. 43(9), pp. 2090-2098.

Kenny, L., Hattersley, C., Molins, B., Buckley, C., Povey, C., and Pellicano, E. (2016). Which terms should be used to describe autism? Perspectives from the UK autism community. Autism, vol. 20(4), pp. 442-462.

Kiami, S. R., and Goodgold, S. (2017). Support needs and coping strategies as predictors of stress level among mothers of children with autism spectrum disorder. Autism Research and Treatment, pp. 1-10.

Knight, K. (2013). The changing face of the 'good mother': trends in research into families with a child with intellectual disability, and some concerns. Disability and Society, vol. 28(5), pp. 660-673.

Levin, A., and Scher, A. (2016). Sleep Problems in Young Children with Autism Spectrum Disorders: A Study of Parenting Stress, Mothers' Sleep-Related Cognitions, and Bedtime Behaviors. CNS Neuroscience and Therapeutics, vol. 22(11), pp. 921-927.

Liao, Y., Dillenburger, K., and Buchanan, I. (2018). Does culture matter in ABA-based autism interventions? Parent and professional experiences in the UK and China. European Journal of Behavior Analysis, vol.19(1), pp. 11-29.

Morgan, P. (2017). Child protection and parents with a learning disability; good practice for assessing and working with adults. London: Jessica Kingsley Publishers.

Morris, L. A. (2012). Testing respite effect of work on stress among mothers of children with special needs. Journal of Family and Economic Issues, vol. 33(1), pp. 24-40.

National Institute of Clinical Excellence (2012). Autism spectrum disorder in under 19s: support and management. Accessed on 13/05/2019 at: https://www.nice.org.uk/guidance/cg170.

Nealy, C. E., O'Hare, L., Powers, J. D., and Swick, D. C. (2012). The impact of autism spectrum disorders on the family: A qualitative study of mothers' perspectives. Journal of Family Social Work, vol. 15(3), pp. 187-201.

Nomaguchi, K., and Johnson, W. (2016). Parenting stress among low-income and workingclass fathers: The role of employment. Journal of Family Issues, 37(11), 1535-1557.

Neece, C. and Chan, N. (2017). The stress of parenting children with developmental disabilities, pp. 107-124, in Deater-Deckard, K. and Panneton, R. (2017), Parental stress and early child development. Switzerland: Springer. 
Neely-Barnes, S. L., Hall, H. R., Roberts, R. J., and Graff, J. C. (2011). Parenting a child with an autism spectrum disorder: Public perceptions and parental conceptualizations. Journal of Family Social Work, vol. 14(3), pp. 208-225.

NICCY (2018). Still Waiting. Belfast. Accessed on 13/05/2019 at: https://www.niccy.org/media/3114/niccy-still-waiting-report-sept-18-web.pdf.

Osborne, L. A., McHugh, L., Saunders, J., and Reed, P. (2008). Parenting stress reduces the effectiveness of early teaching interventions for autistic spectrum disorders. Journal of Autism and Developmental Disorders, vol. 38, pp. 1092-1103.

Pearlin, L. I. (1989). The sociological study of stress. Journal of Health and Social Behavior, pp. 241-256.

Pepperell, T. A., Paynter, J., and Gilmore, L. (2018). Social support and coping strategies of parents raising a child with autism spectrum disorder. Early Child Development and Care, vol.188(10), pp. 1392-1404.

Picardi, A., Gigantesco, A., Tarolla, E., Stoppioni, V., Cerbo, R., Cremonte, M., and Nardocci, F. (2018). Parental burden and its correlates in families of children with autism spectrum disorder: A multicentre study with two comparison groups. Clinical Practice and Epidemiology in Mental Health: Clinical Practice and Epidemiology in Clinical Practice, vol. 14, pp.143.

Reed, P., Giles, A., White, S., and Osborne, L. A. (2019). Actual and perceived speedy diagnoses are associated with mothers' unresolved reactions to a diagnosis of autism spectrum disorder for a child. Autism, vol. 23(7), 1843-1852.

Rivard, M., Lépine, A., Mercier, C., and Morin, M. (2015). Quality determinants of services for parents of young children with autism spectrum disorders. Journal of Child and Family Studies, vol. 24(8), pp. 2388-2397.

Rodriguez, G., Hartley, S. L., and Bolt, D. (2019). Transactional relations between parenting stress and child autism symptoms and behavior problems. Journal of Autism and Developmental Disorders, vol. 49, pp. 1887-1898.

Seltzer, M. M., Greenberg, J. S., Hong, J., Smith, L. E., Almeida, D. M., Coe, C., and Stawski, R. S. (2010). Maternal cortisol levels and behavior problems in adolescents and adults with ASD. Journal of Autism and Developmental Disorders, vol.40(4), pp.457-469.

Shearn, J., and Todd, S. (2000). Maternal employment and family responsibilities: The perspectives of mothers of children with intellectual disabilities. Journal of Applied Research in Intellectual Disabilities, vol.13(3), pp.109-131.

Sikora, D., Moran, E., Orlich, F., Hall, T. A., Kovacs, E. A., Delahaye, J., and Kuhlthau, K. (2013). The relationship between family functioning and behavior problems in children with autism spectrum disorders. Research in Autism Spectrum Disorders, vol. 7(2), pp. 307-315. 
Sim, A., Vaz, S., Cordier, R., Joosten, A., Parsons, D., Smith, C., and Falkmer, T. (2018). Factors associated with stress in families of children with autism spectrum disorder. Developmental Neurorehabilitation, vol.21(3), pp.155-165.

Smith, R. (2008). Social Work and Power. Basingstoke: Palgrave MacMillan.

Stahmer, A. C., Vejnoska, S., ladarola, S., Straiton, D., Segovia, F. R., Luelmo, P., and Hochheimer, S. (2019). Caregiver voices: Cross-cultural input on improving access to autism services. Journal of Racial and Ethnic Health Disparities, vol. 6(4), pp. 752-773.

Steiner, A. M., and Gengoux, G. W. (2018). Strength-based approaches to working with families of children with ASD, pp. 155-168, in Handbook of parent-implemented interventions for very young children with autism, Switzerland: Springer.

Stroebe, M., Schut, H., and Boerner, K. (2017). Cautioning health-care professionals: Bereaved persons are misguided through the stages of grief. OMEGA-Journal of Death and Dying, vol. 74(4), pp. 455-473.

Sukmak, V., and Sangsuk, N. (2018). Living a tormented life: Caregivers' experiences of caring for a child with autism in Northeastern Thailand. Archives of Psychiatric Nursing, vol. 32(5), pp. 745-750.

Tarver, J., Palmer, M., Webb, S., Scott, S., Slonims, V., Simonoff, E., and Charman, T. (2019). Child and parent outcomes following parent interventions for child emotional and behavioral problems in autism spectrum disorders: A systematic review and meta-analysis. Autism, 23(7), 1630-1644.

Taylor, B.J., Killick, C. and McGlade, A. (2015). Understanding and Using Research in Social Work. London: Sage Publications Ltd.

Teague, S. J., Newman, L. K., Tonge, B. J., and Gray, K. M. (2018). Caregiver mental health, parenting practices, and perceptions of child attachment in children with Autism Spectrum Disorder. Journal of Autism and Developmental Disorders, vol.48(8), pp.2642-2652.

Thompson, N. (2016). The Professional Social Worker: Meeting the Challenge (Second Edition). London: Palgrave Macmillan.

Totsika, V., Hastings, R. P., Emerson, E., Lancaster, G. A., and Berridge, D. M. (2011). A population-based investigation of behavioural and emotional problems and maternal mental health: Associations with autism spectrum disorder and intellectual disability. Journal of Child Psychology and Psychiatry, vol.52(1), pp.91-99.

Winter, K. Neeson, L. Sweet, D., and Connolly, P (2018). Evaluation of the early intervention support service in Northern Ireland. Belfast: Centre for Evidence and Social Innovation, Queen's University Belfast. 
Wolf, M.M., Risley, T.R., and Mees, H. (1964). Application of operant conditioning procedures to the behaviour problems of an autistic child. Behaviour Research and Therapy, vol.1, pp. 305-312.

World Health Organisation (2014). Sixty-seventh World Health Assembly: Comprehensive and coordinated efforts for the management of autism spectrum disorders. Geneva: WHO. Accessed on 12/05/2019 at: https://www.who.int/mental health/maternalchild/WHA67.8 resolution autism.pdf

World Health Organisation (2018). Autism Spectrum Disorders. Accessed on 12/05/2019 at: https://www.who.int/news-room/fact-sheets/detail/autism-spectrum-disorders

Yirmiya, N., and Shaked, M. (2005). Psychiatric disorders in parents of children with autism: a meta-analysis. Journal of Child Psychology and Psychiatry, vol. 46(1), pp. 69-83.

Yorke, I., White, P., Weston, A., Rafla, M., Charman, T., and Simonoff, E. (2018). The association between emotional and behavioral problems in children with autism spectrum disorder and psychological distress in their parents: a systematic review and meta-analysis. Journal of Autism and Developmental Disorders, vol. 48(10), pp. 3393-3415.

Zaidman-Zait, A., Mirenda, P., Duku, E., Szatmari, P., Georgiades, S., Volden, J., and Fombonne, E. (2014). Examination of bidirectional relationships between parent stress and two types of problem behavior in children with autism spectrum disorder. Journal of Autism and Developmental Disorders, vol. 44(8), pp. 1908-1917.

Zibricky, C. D. (2014). New knowledge about motherhood: An autoethnography on raising a disabled child. Journal of Family Studies, vol.20(1), pp.39-47. 